\title{
Spectral characteristics of 5-hydroxymethyl- furfural as a related substance in medicinal products containing glucose
}

\author{
Nataliia Hudz ${ }^{1}$, Dmytro Leontiev², Piotr P. Wieczorek ${ }^{3}$ \\ 1 Department of Drug technology and biopharmacy, Danylo Halytsky Lviv National Medical University, Pekarska street 69, Lviv, Ukraine \\ 2 Ukrainian Scientific Pharmacopoeial Center for Quality of Medicines, Astronomichna street 33, Kharkiv, Ukraine \\ 3 Department of Analytical and Ecological Chemistry, University of Opole, Pl. Kopernika 11, 45-040, Opole, Poland \\ Corresponding author: Nataliia Hudz (natali_gudz@ukr.net)
}

Received 7 May 2019 • Accepted 14 June 2019 • Published 7 November 2019

Citation: Hudz N, Leontiev D, Wieczorek PP (2019) Spectral characteristics of 5-hydroxymethylfurfural as a related substance in medicinal products containing glucose. Pharmacia 66(3): 121-125. https://doi.org/10.3897/pharmacia.66.e35969

\begin{abstract}
Objectives: To study 5-hydroxymethylfurfural (5-HMF) spectral characteristics aiming at their future application in analytical procedures and their validation for the determination of 5-HMF in liquid products containing glucose after sterilization. Method: Direct spectrophotometric method for the determination of 5-HMF using the molar absorption coefficient at the absorption maximum (284 nm).

Results and discussion: aqueous 5-HMF solutions have strong absorption in the ultraviolet range below $310 \mathrm{~nm}$ and give two absorption maxima at wavelengths of 229-230 nm and $284 \mathrm{~nm}$. An excellent linear relationship between absorbance and 5-HMF concentration was observed in the concentration range of $2.0-10.0 \mathrm{mg} / \mathrm{l}$. The linear dependence passes through the origin. The molar absorption coefficients of 5-HMF were determined and found to be $3007 \mathrm{~mol}^{-1} \cdot \mathrm{L} \cdot \mathrm{cm}^{-1}$ at $229-230 \mathrm{~nm}$ and $16070 \mathrm{~mol}{ }^{-1} \cdot \mathrm{L} \cdot \mathrm{cm}^{-1}$ at $284 \mathrm{~nm}$. The use of the molar absorption coefficient of 5-HMF stated in the Pharmacopeia of the United States of America for determining 5-HMF in polydextrose $\left(16830 \mathrm{~mol}^{-1} \cdot \mathrm{L} \cdot \mathrm{cm}^{-1}\right.$ at $\left.283 \mathrm{~nm}\right)$ gives recovery results for model solutions of reference substance of 5-HMF that are acceptable from the point of view of the requirements of the State Pharmacopeia of Ukraine for methods of quantitative determination of impurities. However, other values of the molar absorption coefficient $\left(17000\right.$ and $\left.22700 \mathrm{~mol}^{-1} \cdot \mathrm{L} \cdot \mathrm{cm}^{-1}\right)$ given in the scientific publications are unsuitable for the quantitative determination of 5-HMF as an impurity in medicinal products.

Conclusion: The molar absorption coefficient $\left(16830 \mathrm{~mol}^{-1} \cdot \mathrm{L} \cdot \mathrm{cm}^{-1}\right.$ at $\left.284 \mathrm{~nm}\right)$ may be used to quantify 5 -HMF as an impurity in medicinal products containing glucose. For a specific medicinal product, a full validation of the analytical procedure of the 5-HMF determination is required taking into account the composition of this product.
\end{abstract}

\section{Keywords}

5-hydroxymethylfurfural; spectrophotometric method; molar absorption coefficient, medicinal products containing glucose 


\section{Introduction}

In the pharmaceutical industry, heat sterilization is widely applied to medicinal products in liquid dosage forms. Steam sterilization is considered to be sterilization of choice (Hanrahan et al. 2012). Although conditions vary, sterilization typically occurs at $121{ }^{\circ} \mathrm{C}$ for $20-60$ or even 80 minutes (Hanrahan et al. 2012; Kjellstrand et al. 2004). Colour and 5-HMF contents are important quality indexes in sterilized liquid medicinal products which contain glucose as an active pharmaceutical ingredient (Kjellstrand et al. 2004; Hudz et al. 2018; BP 2009). Among such medicinal products are solutions for infusions and peritoneal dialysis. The results of numerous experimental studies indicated that 5-HMF as a toxic furanic compound is formed by glucose decomposition under neutral or acidic conditions during thermal sterilization (Kjellstrand et al. 2004; Hudz et al. 2018). High levels of 5-HMF may be the result of inadequate sterilization and/or storage of medicinal products at elevated temperatures (Hudz et al. 2018). Therefore, it is very important to determine concentration of 5-HMF in medicinal products containing glucose after heat sterilization. It should be noted that 5 -HMF is a very important quality index for food products as well (Zappalaet al. 2005).

Quality control of peritoneal dialysis solutions is performed according to the monograph of the British Pharmacopeia. This monograph provides analytical procedures for measuring the 5-HMF concentrations based on the colored product which is formed as a result of the reaction between 5-HMF, $p$-toluidine in 2-propanol containing glacial acetic acid and barbituric acid (BP 2009). High pressure liquid chromatography method is one more method for the determination of 5-HMF, which requires expensive analytical equipment (BP 2009; Zappala et al. 2005). Monograph of the Pharmacopeia of the United States of America (USP) proposes to determine 5-HMF in polydextrose using the molar absorption coefficient $\varepsilon$ (Polydextrose). This analytical procedure is very suitable as it is fast and simple and allows performing measurements on a very large amount of samples. Moreover, this procedure does not use toxic reagents. To the best of our knowledge, there is no single value of the molar absorption coefficient $\varepsilon$ for 5-HMF. There are two more values described in the publications which differ significantly between each other and from the value stated in the USP (Kjellstrand et al. 2004; Polydextrose; Zhang et al. 2013). However, the suitability of the USP analytical procedure for analyzing glucose solutions must be justified. Therefore, the possibility of correct applying molar absorption coefficient $\varepsilon$ to the 5-HMF quantification in solutions containing glucose is a topical issue in pharmaceutical analysis. To solve this problem, firstly it is necessary to study the spectral characteristics of 5-HMF and establish its molar absorption coefficients at the wavelengths of maximum absorption.

The State Pharmacopoeia of Ukraine establishes requirements for the maximum permissible uncertainty of analysis results $\left(\max \Delta_{\mathrm{As}}\right)$ based on the risk of making an incorrect conclusion on compliance with specifications (The State Pharmacopoeia of Ukraine). A reliability level of $95 \%$ is considered as acceptable. It is recommended that $\max \Delta_{\mathrm{As}}$ should not exceed $5 \%$ for quantitative determination of impurities. The existing methods for determining 5-HMF content were not analyzed in terms of the risk of making an incorrect decision and in terms of the requirements for $\max \Delta_{\mathrm{As}}$.

The primary aim of this research was to study the 5-HMF spectral characteristics, linearity, intermediate precision, range, detection limit, quantitation limit of the analytical procedure of the 5-HMF determination and estimate the possibility of using molar absorption coefficient $\varepsilon$ for 5 -HMF assay in liquid medicinal products containing glucose from the point of view of the risk of making an incorrect decision in accordance with the approaches of the State Pharmacopeia of Ukraine (The State Pharmacopoeia of Ukraine). Our secondary goal was to study the repeatability of the 5-HMF spectral characteristics and compare them with literature data as well.

\section{Reagents}

5-HMF (analytical standard, batch number: BCBR3219V) was purchased from Sigma-Aldrich (USA). It was dissolved in purified water before analysis. As stock solutions were ones with 5-HMF concentrations of $19.7 \mathrm{mg} / \mathrm{L}$ (the first experiment) and $19.9 \mathrm{mg} / \mathrm{L}$ (the second experiment for the intermediate precision estimation).

\section{Method}

Direct spectrophotometric method of the 5-HMF determination was employed.

The five aqueous 5-HMF solutions with the concentrations in the range of $2-10 \mathrm{mg} / \mathrm{L}$ were prepared using purified water as a solvent. The 5-HMF concentrations were calculated using the known values of the molar absorption coefficient $\varepsilon$ for 5-HMF at the wavelength of maximum absorption at 283-284 $\mathrm{nm}$ according to the following formula:

$$
C=\frac{A \bullet M . m \cdot \bullet 10^{4}}{10 \bullet \varepsilon}=\frac{A \bullet M \cdot m \cdot \bullet 10^{3}}{\varepsilon}
$$

where C - 5-HMF concentration in $\mathrm{mg} / \mathrm{L}, \mathrm{A}$ - solutions absorbance at an absorption maximum of 283-284 nm, M.m. - molar mass of 5-HMF (126 g/mol), $\varepsilon-$ molar absorption coefficient.

\section{Analytical equipment}

Spectrophotometer Hitachi U-2810 (Hitachi High-Technologies Corporation, Japan) was used. A 1-cm quartz cell was used over the range of 200 to $350 \mathrm{~nm}$. 


\section{Results and discussion}

It was shown in a published paper (Hudz et al. 2018) that 5-HMF solutions has a strong absorption in the ultraviolet range below $310 \mathrm{~nm}$ and had two absorption maxima at the wavelengths of $229-230 \mathrm{~nm}$ (the first maximum) and $284 \mathrm{~nm}$ (the second maximum) (Fig. 1).

Moreover, the ratio of the absorbances at these two absorbtion maxima $\left(\mathrm{A}_{284}: \mathrm{A}_{228}\right)$ was in the range of 5.04-5.65 that almost conforms to data provided by Kjellstrand et al. (2004), who had provided that ratio as 5.7 (Kjellstrand et al. 2004). It was also found that the absorbance of 5-HMF at $284 \mathrm{~nm}$ follows Beer's law very well $(\mathrm{r}=0.999)$ in the concentrations range of $2-10 \mathrm{mg} / \mathrm{L}$. This correlation is presented in Fig. 2. Standard deviations (SD) for y-intercept and slope were, respectively, 0.0039 and 0.00059, and residual $\mathrm{SD}\left(\mathrm{SD}_{0}\right)$ for the calibration line was 0.0037 .

For the study of intermediate precision experiments were performed twice. The second experiment was repeated in 5 months using the same spectrophometer and the same batch of 5-HMF as a reference substance. Fig. 3 shows the correlation between absorbance and 5-HMF concentration for the second experiment. SD for $y$-intercept and slope were, respectively, 0.00694 and 0.00105 , $\mathrm{SD}_{0}$ was 0.00662 . The second study confirmed the spectral characteristic of 5-HMF, namely the two absorption maxima at the wavelengths of 229-230 nm and $284 \mathrm{~nm}$.

The detailed spectral characteristic of 5-HMF in the first and second experiments are given in Tables 1 and 2.

The condition for the correct application of the molar absorption coefficient $\varepsilon$ is also the passage of a linear dependence through the origin. To calculate the confidence interval, one-tailed Student coefficient for the level of reliability of $95 \%$ and number of freedom degrees $v=5-2$ $=3(t=2.3534)$ was used. For the both experiments, the $y$-intercepts did not exceed their confidence interval that confirms the correctness of using the molar absorption coefficient to determine 5-HMF content.

We also experimentally determined molar absorption coefficient for 5-HMF at 229-230 nm. To the best of our knowledge, only one available publication provides the value of the molar absorption coefficient for 5-HMF at $228 \mathrm{~nm}$, which is equal to $3000 \mathrm{~L} \cdot \mathrm{mol}^{-1} \cdot \mathrm{cm}^{-1}$ (Kjellstrand et al. 2004). Therefore, one more task of this study was to calculate as well the molar absorption coefficient for 5-HMF at 228-230 $\mathrm{nm}$ on the base of own experimental data using the following formula:

$$
\varepsilon=\frac{A \bullet M \cdot m \cdot \bullet 10^{3}}{C}
$$

where A - solutions absorbance at the first absorption maximum, M.m. - molar mass of 5-HMF (126 g/mol), C - 5-HMF concentration in $\mathrm{mg} / \mathrm{L}$.

The molar absorption coefficient of 5-HMF at 229-230 $\mathrm{nm}$ was determined and found to be $3007 \mathrm{~mol}^{-1} \cdot \mathrm{L} \cdot \mathrm{cm}^{-1}$ that is in line with data of Kjellstrand et al. (2004).

It can be seen that very similar values were obtained for the molar absorption coeffitients of 5-HMF in the same

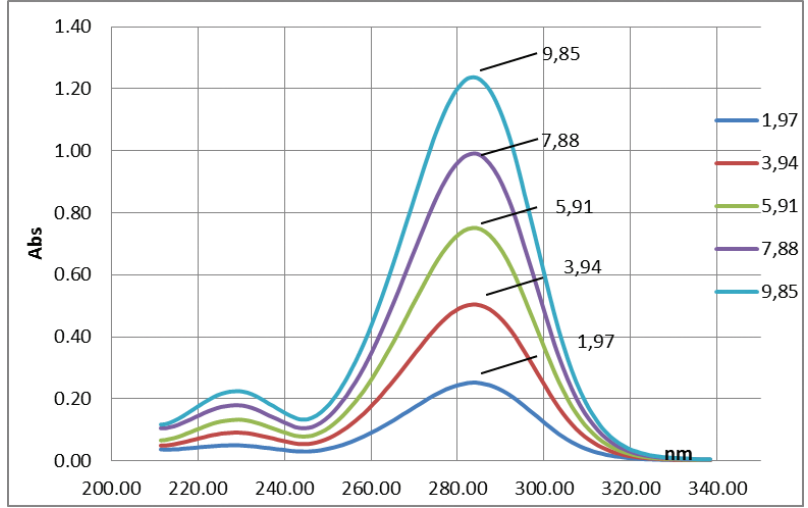

Figure 1. Spectra of 5-HMF at the concentrations of 1.97 $\mathrm{mg} / \mathrm{L}, 3.94 \mathrm{mg} / \mathrm{L}, 5.91 \mathrm{mg} / \mathrm{L}, 7.88 \mathrm{mg} / \mathrm{L}$, and $9.85 \mathrm{mg} / \mathrm{L}$ (Hudz et al. 2018).

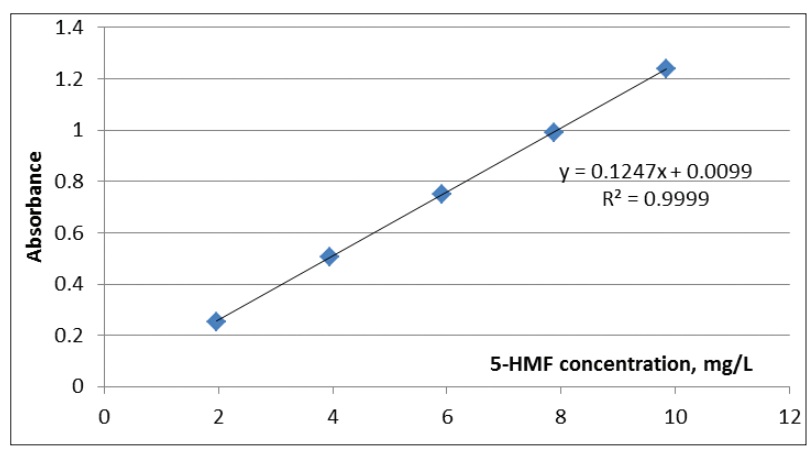

Figure 2. Correlation between absorbance at $284 \mathrm{~nm}$ and 5-HMF concentration in the first experiment.

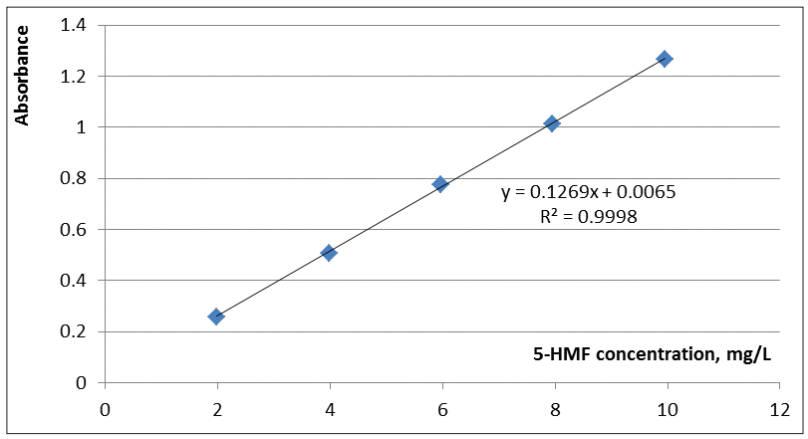

Figure 3. Correlation between absorbance at $284 \mathrm{~nm}$ and 5 -HMF concentration in the second experiment.

laboratory at different days. The mean of two experiments was $3007 \mathrm{~mol}^{-1} \cdot \mathrm{L} \cdot \mathrm{cm}^{-1} \pm 3.26 \%$ at $229-230 \mathrm{~nm}$ and 16070 $\mathrm{mol}^{-1} \cdot \mathrm{L} \cdot \mathrm{cm}^{-1} \pm 0.76 \%$ at $284 \mathrm{~nm}$. These deviations $(3.26 \%$ and $0.76 \%$ ) did not exceed the requirements of the State Pharmacopeia of Ukraine for $\max \Delta_{\mathrm{As}}$ for methods of quantitative determination of impurities $\left(\max \Delta_{\mathrm{As}} \leq 5 \%\right)$. Consequently, the elaborated procedure is characterized by good intermediate precision.

The following values of the molar absorption coefficient $\varepsilon$ for 5-HMF at an absorption maximum of 283-284 $\mathrm{nm}$ were used for the estimation of the analytical procedure recovery:

1. $17000 \mathrm{~mol}^{-1} \cdot \mathrm{L} \cdot \mathrm{cm}^{-1}$ (Kjellstrand et al. 2004);

2. $22700 \mathrm{~mol}^{-1} \cdot \mathrm{L} \cdot \mathrm{cm}^{-1}$ (Zhang et al. 2013);

3. $16830 \mathrm{~mol}^{-1} \cdot \mathrm{L} \cdot \mathrm{cm}^{-1}$ (Polydextrose). 
Table 1. Detailed spectral characteristic of 5-HMF (01 August 2016).

\begin{tabular}{|c|c|c|c|c|c|c|c|c|}
\hline \multirow{2}{*}{$\begin{array}{c}\text { 5-HMF } \\
\text { concentration, } \\
\mathrm{mg} / \mathrm{L}\end{array}$} & \multirow{2}{*}{$\begin{array}{c}\text { Wavelengths } \\
\text { of maximum } \\
\text { absorption, } \lambda_{\max }, \mathrm{nm}\end{array}$} & \multirow{2}{*}{$\begin{array}{l}\text { Absorbance at } \\
\text { the absorption } \\
\text { maxima (A) }\end{array}$} & \multirow{2}{*}{$\begin{array}{c}\text { Ratio } \\
A_{\lambda 1}: A_{\lambda 2}\end{array}$} & \multicolumn{2}{|c|}{ Found values of $\varepsilon$ at } & \multicolumn{3}{|c|}{$\%$ recovery at $\varepsilon$ values } \\
\hline & & & & $229 \mathrm{~nm}$ & $284 \mathrm{~nm}$ & 16830 & 17000 & 22700 \\
\hline \multirow[t]{2}{*}{1.97} & $\lambda_{1}=284.2$ & 0.252 & 5.04 & 3198 & 16118 & 95.77 & 94.81 & 71.00 \\
\hline & $\lambda_{2}=228.0$ & 0.050 & & & & & & \\
\hline \multirow[t]{2}{*}{3.94} & $\lambda_{1}=283.8$ & 0.504 & 5.54 & 2910 & 16118 & 95.77 & 94.81 & 71.00 \\
\hline & $\lambda_{2}=229.4$ & 0.091 & & & & & & \\
\hline \multirow[t]{2}{*}{5.91} & $\lambda_{1}=283.8$ & 0.751 & 5.65 & 2836 & 16011 & 95.13 & 94.18 & 70.53 \\
\hline & $\lambda_{2}=229.4$ & 0.133 & & & & & & \\
\hline \multirow[t]{2}{*}{7.88} & $\lambda_{1}=284.0$ & 0.991 & 5.54 & 2862 & 15846 & 94.15 & 93.21 & 69.81 \\
\hline & $\lambda_{2}=229.0$ & 0.179 & & & & & & \\
\hline \multirow[t]{2}{*}{9.85} & $\lambda_{1}=284.0$ & 1.237 & 5.50 & 2878 & 15824 & 94.02 & 93.08 & 69.71 \\
\hline & $\lambda_{2}=229.2$ & 0.225 & & & & & & \\
\hline \multirow[t]{2}{*}{ mean $\pm \mathrm{SD}$} & $\lambda_{1}=284.0 \pm 0.2$ & - & $5.45 \pm 0.24$ & $2937 \pm 149$ & $15983 \pm 143$ & $94.97 \pm 0.85$ & $94.02 \pm 0.84$ & $70.41 \pm 0.62$ \\
\hline & $\lambda_{2}=229.0 \pm 0.6$ & & & & & & & \\
\hline mean $\pm \%$ RSD & - & - & - & $2937 \pm 5.1 \%$ & $15983 \pm 0.89 \%$ & $94.97 \pm 0.90 \%$ & $94.02 \pm 0.89 \%$ & $70.41 \pm 0.88 \%$ \\
\hline
\end{tabular}

Table 2. Detailed spectral characteristic of 5-HMF (10 December 2016).

\begin{tabular}{|c|c|c|c|c|c|c|c|c|}
\hline \multirow{2}{*}{$\begin{array}{c}\text { 5-HMF } \\
\text { concentration, } \\
\mathrm{mg} / \mathrm{L}\end{array}$} & \multirow{2}{*}{$\begin{array}{c}\text { Wavelengths } \\
\text { of maximum } \\
\text { absorption, } \lambda_{\max }, \mathrm{nm}\end{array}$} & \multirow{2}{*}{$\begin{array}{l}\text { Absorbance at } \\
\text { the absorption } \\
\text { maxima }(\mathrm{A})\end{array}$} & \multirow{2}{*}{$\begin{array}{c}\text { Ratio } \\
A_{\lambda 1}: A_{\lambda 2}\end{array}$} & \multicolumn{2}{|c|}{ Found values of $\varepsilon$ at } & \multicolumn{3}{|c|}{$\%$ recovery at $\varepsilon$ values } \\
\hline & & & & $229 \mathrm{~nm}$ & $284 \mathrm{~nm}$ & 16830 & 17000 & 22700 \\
\hline \multirow[t]{2}{*}{1.99} & $\lambda_{1}=284.0$ & 0.258 & 5.27 & 3103 & 16336 & 97.06 & 96.09 & 71.96 \\
\hline & $\lambda_{2}=230.2$ & 0.049 & & & & & & \\
\hline \multirow[t]{2}{*}{3.98} & $\lambda_{1}=284.0$ & 0.507 & 5.28 & 3039 & 16051 & 95.37 & 94.42 & 70.71 \\
\hline & $\lambda_{2}=229.5$ & 0.096 & & & & & & \\
\hline \multirow[t]{2}{*}{5.97} & $\lambda_{1}=284.0$ & 0.774 & 5.27 & 3103 & 16336 & 97.06 & 96.09 & 71.96 \\
\hline & $\lambda_{2}=229.5$ & 0.147 & & & & & & \\
\hline \multirow[t]{2}{*}{7.96} & $\lambda_{1}=284.0$ & 1.014 & 5.34 & 3008 & 16051 & 95.37 & 94.42 & 70.71 \\
\hline & $\lambda_{2}=229.5$ & 0.190 & & & & & & \\
\hline \multirow[t]{2}{*}{9.95} & $\lambda_{1}=284.0$ & 1.264 & 5.31 & 3027 & 16006 & 95.11 & 94.16 & 70.51 \\
\hline & $\lambda_{2}=229.5$ & 0.238 & & & & & & \\
\hline \multirow[t]{2}{*}{ mean $\pm \mathrm{SD}$} & $\lambda_{1}=284.0 \pm 0.0$ & - & $5.29 \pm$ & $3076 \pm 56$ & $16156 \pm 165$ & $95.99 \pm 0.98$ & $95.04 \pm 0.97$ & $71.17 \pm 0.73$ \\
\hline & $\lambda_{2}=229.7 \pm 0.3$ & & 0.03 & & & & & \\
\hline mean $\pm \%$ RSD & - & - & - & $3076 \pm 1.82 \%$ & $16156 \pm 1.02 \%$ & $95.99 \pm 1.02 \%$ & $95.04 \pm 1.02 \%$ & $71.17 \pm 1.03 \%$ \\
\hline
\end{tabular}

The average recovery values for the molar absorption coefficients were calculated for each experiment (Tables 1 , 2). The average recovery was calculated as mean from the both experiments. For a value of $16830 \mathrm{~mol}^{-1} \cdot \mathrm{L} \cdot \mathrm{cm}^{-1}$ from USP-NF (Polydextrose), the mean recovery is equal to $95.5 \%$. Such a deviation from $100 \%$ is acceptable based on the criterion of the State Pharmacopeia of Ukraine $\left(\Delta_{\mathrm{As}} \leq\right.$ $5 \%)$. However, for a value of $17000 \mathrm{~mol}^{-1} \cdot \mathrm{L} \cdot \mathrm{cm}^{-1}$ (Kjellstrand et al. 2004) the recovery was equal to $94.53 \%$, which slightly exceeds the criterion of the State Pharmacopeia of Ukraine. For $22700 \mathrm{~mol}^{-1} \cdot \mathrm{L} \cdot \mathrm{cm}^{-1}$ (Zhanget al. 2013), the mean recovery was a significantly lower (70.79\%) and it was obviously unacceptable for pharmaceutical analysis. Thus, the correctness of the obtained experimental value of the molar absorption coefficient $\varepsilon$ for 5 -HMF at $284 \mathrm{~nm}$ is confirmed by the value stated in the USP. Other values of $\varepsilon$ for 5 -HMF at 283-284 $\mathrm{nm}$ described in the publications (17000 and 22700 $\mathrm{mol}^{-1} \cdot \mathrm{L} \cdot \mathrm{cm}^{-1}$ ) are unsuitable for the quantitative determination of 5-HMF as an impurity in medicinal products.

Limit of detection (LoD) and limit of quantification (LoQ) were calculated from the SD of y-intercept and the slope of the calibration lines (The State Pharmacopoeia of Ukraine 2018; Technical Guide for the Elaboration of Monographs). In the first and second experiments, these values were as follows: $\mathrm{LoD} \approx 0.10$ and $\mathrm{LoQ} \approx 0.30 \mathrm{mg} / \mathrm{l}$, and $\mathrm{LoD} \approx 0.18$ and $\mathrm{LoQ} \approx 0.53 \mathrm{mg} / \mathrm{l}$, respectively. It can be seen that the obtained LoD and LoQ values are significantly lower than the experimental concentration range, which is a consequence of very good linearity of the elaborated analytical procedure. However, it is possible to evaluate the practical significance of these assessments only simultaneously with the validation of the analytical procedure for determining 5-HMF in a real medicinal or food product taking into consideration a product composition with the purpose of establishing specificity of the analytical procedure for the product.

Thus, the developed direct spectrophotometric method of the 5-HMF quantitative determination using the molar absorption coefficient at $283-284 \mathrm{~nm}$ is potentially suitable for medicinal products containing glucose.

\section{Conclusions}

A linear relationship between absorbance and HMF concentration was observed in the concentration range of 2-10 mg/l. The linear dependence passes through the origin. The molar absorption coefficients of 5-HMF were determined and found to be $3007 \mathrm{~mol}^{-1} \cdot \mathrm{L} \cdot \mathrm{cm}^{-1}$ at 229 $230 \mathrm{~nm}$ and $16070 \mathrm{~mol}^{-1} \cdot \mathrm{L} \cdot \mathrm{cm}^{-1}$ at $284 \mathrm{~nm}$. The use of the molar absorption coefficient of 5-HMF at $284 \mathrm{~nm}$ gives 
results that are acceptable from the point of view of the requirements of the State Pharmacopeia of Ukraine for methods of quantitative determination of impurities. The method could be potentially applied to the determination of 5-HMF, provided that validation of the analytical procedure for each medicinal product is studied.

\section{References}

BP [British Pharmacopoeia Commission] (2009) British Pharmacopoeia. The Stationery Office, London, 10952 pp.

Hanrahan CT, Himmele R, Diaz-Buxo JA (2012) The challenges of heat sterilization of peritoneal dialysis solutions: is there an alternative? Advances in Peritoneal Dialysis 28: 126-130.

Hudz N, Korzeniowska K, Wieczorek PP (2018) Chemical transformations of glucose in solutions for peritoneal dialysis after sterilization and during storage. Acta Poloniae Pharmaceutica. Drug Research 4: 875-883. https://doi.org/10.32383/appdr/81134

Kjellstrand P, Erixon M, Wieslander A, Lindén T, Martinson E (2004) Temperature: the most important factor for degradation of glucose fluid during storage. Peritoneal Dialysis International 4: 385-391.

\section{Acknowledgement}

Co-author Natalia Hudz is grateful to the International Visegrad Fund for providing scholarship for studies related to solutions for dialysis therapy.

The State Pharmacopoeia of Ukraine (2018) Kharkiv: State Enterprise "Ukrainian Scientific Pharmacopoeial Center for the Quality of Medicinal Products" (2 $2^{\text {nd }}$ edn). $416 \mathrm{pp}$.

European Directorate for the Quality of Medicines (2015) Technical Guide for the Elaboration of Monographs ( $7^{\text {th }}$ edn). European Pharmacopoeia, Strasbourg, $67 \mathrm{pp}$.

Zappala M, Fallico B, Arena E, Verzera A (2005) Methods for the determination of HMF in honey: A comparison. Food Control 16: 273 277. https://doi.org/10.1016/j.foodcont.2004.03.006

Zhang J, Li J, Tang Y, Xue G (2013) Rapid method for the determination of 5-hydroxymethylfurfural and levulinic acid using a double-wavelength UV spectroscopy. The Scientific World Journal 2013: e506329. https://doi.org/10.1155/2013/506329 